\title{
PERIPHERAL ULCERATIVE KERATITIS AND RHEUMATOID ARTHRITIS: A CASE REPORT
}

Izabela Guimaraes Vieira Coelho ${ }^{1, \star}$, Gustavo Lamego de Barros Costa ${ }^{1}$, Juliana Cabrera Garrido ${ }^{1}$, Corina Quental de Menezes Alvarenga ${ }^{1}$, Filipe Didier Maciel ${ }^{1}$, Gustavo Braga Hallais França ${ }^{1}$

1.Santa Casa de Misericórdia de Belo Horizonte, Belo Horizonte (MG), Brazil.

*Corresponding author: izabela_guimaraes@hotmail.com

\section{BACKGROUND}

Peripheral ulcerative keratitis (PUK) is a rare manifestation characterized by progressive thinning of the peripheral cornea, and the clinical manifestation is marked by eye pain, in addition to eye irritation, redness, photophobia and corneal opacification. It may evolve to corneal perforation if not treated initially. It is important to rule out the presence of secondary bacterial infections in the case of peripheral ulcerative keratitis. It is associated with advanced rheumatoid arthritis and the presence of rheumatoid factor in high titers. It is not an exclusive condition of rheumatoid arthritis and can also be seen in cases of granulomatosis with polyangiitis, relapsing polychondritis, systemic lupus erythematosus and systemic sclerosis. The immunosuppressive treatment should be promptly initiated, and the use of systemic corticotherapy, cyclophosphamide, cyclosporine, methotrexate, azathioprine and, more recently, anti-TNF and anti-IL6 should be described. Local treatment with cyanoacrylate glue and corneal flap grafts are also described. Topical corticosteroids are ineffective for treatment and may accelerate corneal slimming and increase the risk of perforation.

\section{CASE REPORT}

A 65-year-old female patient with rheumatoid arthritis since 2013, but with no follow-up nor treatment since 2018, and no joint activity. She was admitted on May 19, 2020 to the Santa Casa of Belo Horizonte eye clinic with a diagnosis of peripheral ulcerative keratitis. In the initial evaluation of ophthalmology, it was seen that the patient presented "hot right eye, with corneal thinning and superior temporal perforation with tamponade on iris". In the requested propaedeutic, she presented RF of $64 \mathrm{U} / \mathrm{mL}$ and anti-CCP $200 \mathrm{U} / \mathrm{mL}$. Patient received pulse therapy of $500 \mathrm{mg}$ methylprednisolone for 3 days and cyclophosphamide ( $500 \mathrm{mg} / \mathrm{dose}$ ), with sequential treatment with $40 \mathrm{mg}$ prednisone and cyclophosphamide IV for 3 months. After stabilization, the patient underwent corneal transplant.

\section{CONCLUSION}

Patients with rheumatoid arthritis who present any ocular alteration characterized by pain, eye irritation or redness should be promptly referred to early ophthalmologic evaluation because it may be a case of peripheral ulcerative keratitis. Ophthalmologists and rheumatologists should act together in these situations for rapid identification and appropriate treatment. 